\title{
The effects of country-level population policy for enhancing adaptation to climate change
}

\author{
N. K. Gunasekara ${ }^{1}$, S. Kazama ${ }^{2}$, D. Yamazaki ${ }^{3}$, and T. Oki ${ }^{4}$ \\ ${ }^{1}$ Graduate School of Environmental Studies, Tohoku University, 6-6-20 Aramaki, Aoba, Sendai, 980-8579, Japan \\ ${ }^{2}$ Department of Civil Engineering, Tohoku University, 6-6-06 Aramaki, Aoba, Sendai, 980-8579, Japan \\ ${ }^{3}$ School of Geographical Science, University of Bristol, University Road, Bristol, BS8 1SS, UK \\ ${ }^{4}$ Institute of Industrial Science, The University of Tokyo, 4-6-1 Komaba, Meguro, Tokyo, 153-8505, Japan
}

Correspondence to: N. K. Gunasekara (nilupulk.gunasekara@gmail.com, nilupul@kaigan.civil.tohoku.ac.jp)

Received: 1 May 2012 - Published in Hydrol. Earth Syst. Sci. Discuss.: 3 August 2012

Revised: 19 September 2013 - Accepted: 2 October 2013 - Published: 12 November 2013

\begin{abstract}
The effectiveness of population policy in reducing the combined impacts of population change and climate change on water resources is explored. One no-policy scenario and two scenarios with population policy assumptions are employed in combination with water availability under the SRES scenarios A1b, B1 and A2 for the impact analysis. The population data used are from the World Bank. The river discharges per grid of horizontal resolution $0.5^{\circ}$ are obtained from the Total Runoff Integrating Pathways (TRIP) of the University of Tokyo, Japan. Unlike the population scenarios utilized in the SRES emission scenarios and the newest representative concentration pathways, the scenarios employed in this research are based, even after 2050, on country-level rather than regional-level growth assumptions.

Our analysis implies that the heterogeneous pattern of population changes across the world is the dominant driver of water stress, irrespective of future greenhouse gas emissions, with highest impacts occurring in the already water-stressed low latitudes. In 2100, Africa, Middle East and parts of Asia are under extreme water stress under all scenarios. The sensitivity analysis reveals that a small reduction in populations over the region could relieve a large number of people from high water stress, while a further increase in population from the assumed levels (SC1) might not increase the number of people under high water stress considerably. Most of the population increase towards 2100 occurs in the already water-stressed lower latitudes. Therefore, population reduction policies are recommended for this region as a method of adaptation to the future water stress conditions. Population reduction policies will facilitate more control over their
\end{abstract}

future development pathways, even if these countries were not able to contribute significantly to greenhouse gas (GHG) emission cuts due to economic constraints. However, for the European region, the population living in water-stressed regions is almost 20 times lower than that in the lower latitudes.

For countries with high population momentum, the population policy scenario with fertility-reduction assumptions gained a maximum of 6.1 times the water availability in Niger and 5.3 times that in Uganda compared with the nopolicy scenario. Most of these countries are in sub-Saharan Africa. These countries represent $24.5 \%$ of the global population in the no-policy scenario, and the scenario with fertility-reduction assumptions reduces it to $8.7 \%$ by 2100 . This scenario is also effective in reducing the area under extreme water stress in these countries. However, the policy scenario with assumptions of population stabilization at the replacement fertility rate increases the water stress in highlatitude countries. Nevertheless, the impact is low due to the high per capita water availability in the region. This research is expected to widen the understanding of the combined impacts of climate change in the future and of the strategies needed to enhance the space for adaptation.

\section{Introduction}

Global water resource assessments project grim futures, with increased water stress in many parts of the world (Vorosmarty et al., 2000; Arnell, 2004; Arnell et al., 2011; Murray et al., 2012). Arnell (2004) projects $36.5-57.2 \%$ of 
the population to be in water-stressed countries (runoff less than $1000 \mathrm{~m}^{3} /$ capita/year) in 2085 as a result of only population increase, while in 1995, it was only $2.0 \%$. However, Arnell et al. (2011) project the same to be $43 \%$ in 2100. Even though for some regions such as Asia climate change alleviates water stress to a certain extent (Arnell et al., 2011; Murray et al., 2012), for Asia and Africa the effect of population change to increase water stress cannot be overlooked. Adaptation measures to reduce the severity of the impacts, therefore, are a must. Population policy (Das Gupta et al., 2011; United Nations, 2011b) and climate policy interventions (Clarke et al., 2009; Moss et al., 2010), early warning systems, effective risk communication between decision makers and citizens, sustainable land management and ecosystem management and restoration (IPCC, 2012) are among the adaptation measures with high potential benefits. However, few studies have specifically quantified the effects of changes in population (Curtis and Schneider, 2011; IPCC, 2012). Nevertheless, societal development trends play significant roles in climate change adaptation compared with specific climate policies (Vorosmarty et al., 2000; Van Vuuren et al., 2010). Furthermore, the global population projections utilized in the new representative concentration pathways (RCPs) and other emissions scenarios (IPCC, 2000, EMF22 cited in Van Vuuren et al., 2010; Riahi et al., 2011) have uniform regional growth assumptions after the year 2050 (Arnell, 2004; Van Vuuren et al., 2010; Riahi et al., 2011). Therefore, their use in climate impact assessments (Arnell, 2004; Shen et al., 2008; Arnell et al., 2011; Murray et al., 2012) masks vulnerabilities as a result of population growth below the regional scale. Most of these studies (Arnell, 2004; IPCC, 2000; Riahi et al., 2011) employ either the United Nations population projections or those of the International Institute of Applied Systems Analysis (IIASA). The projected global populations in 2100 vary significantly among the various projections. The EMF-22 scenarios utilize a population projection of 8 to 10 billion in 2100 (cited in Van Vuuren et al., 2010), whereas the recent RCP population projections vary from approximately 8 to 12 billion (Van Vuuren et al., 2010; Riahi et al., 2011). However, the 2100 population projections used in the previous SRES scenarios (IPCC, 2000) vary from 7 billion under the A1 and B1 storylines to 15 billion under the A2 storyline (IPCC, 2000). Although more recent literature provides more downward projections for 2100 (Van Vuuren and O'Neill, 2006), the most recent World Population Prospects 2010 revision provides a different picture, with slight upward revisions of its 2008 version. The high variant projects a global population of 15.8 billion, whereas the medium and low variants project values of 10.1 and 6.2 billion, respectively (United Nations, 2011a). The reasons for this upward shift are the confirmed evidence of the decreasing prevalence of HIV/AIDS among the third world populations and the slow progress of the fertility decline in sub-Saharan Africa compared to the previous expectations (Lee, 2011). Even though the UN low projection (United Nations, 2011a) gives a declining global population in the second half of the century, the National Research Council (NRC, 2000) has found only a 1 in 1 thousand probability that the global population will decline from 2030 to 2050, in contrast to the UN low scenario (Lee, 2011). However, the UN and IIASA scenarios explicitly assume that the population growth will not change course due to feedback from negative environmental or climate change impacts (Lee, 2011). Therefore, to address these needs, we explore the impacts of a global population projection that results in a total global population similar to that of the UN high population projection (United Nations, 2011a) in 2100, as a result of country-level growth assumptions even after 2050. The climate change impact addressed here is the potential decrease in per capita water resources. The effectiveness of population control policies adopted by a few countries to reduce the combined impacts of population and climate changes globally and regionally is also explored, by the means of two other major population scenarios that assume country-level population policy. Population control is an effective way to reduce the current trend of energy exploitation and the harmful environmental impacts of sprawling urbanization (Koutsoyiannis et al., 2009). Here, population policies are tested as one of the possible low-regrets measures (IPCC, 2012) to reduce the effects of combined population and climate changes. A sensitivity analysis is carried out in order to understand the relative influence of the climate and population drivers of water stress.

\section{Methodology}

\subsection{Population scenarios used}

A scenario that projects the global population to be 15.7 billion in 2100 (SC1, Fig. 1a) was employed without any assumptions regarding additional population control policies directed at tackling climate change for any country. This scenario closely agrees with the UN's high population projection (United Nations, 2011a) of 15.8 billion in 2100. However, only the decadal trends in the historical annual population growth rate (1961-2010) data (World Bank, 2012) at the regional level (for the countries in the three World Bank income categories: high, middle and low income) were explored to derive the future trends. Although the concurrent scenarios used in climate research utilize regionally uniform population growth rates (Arnell, 2004; Van Vuuren et al., 2010) after 2050, this study assumes regional trends in the annual population growth rate. Distinctive trends were derived regionally for trends in the annual population growth rate in the high-, middle- and low-income countries (World Bank, 2012). The year 2010 was taken as the base year for population projections, whereas the base year for this analysis was assumed to be 2000 . Therefore, every scenario 


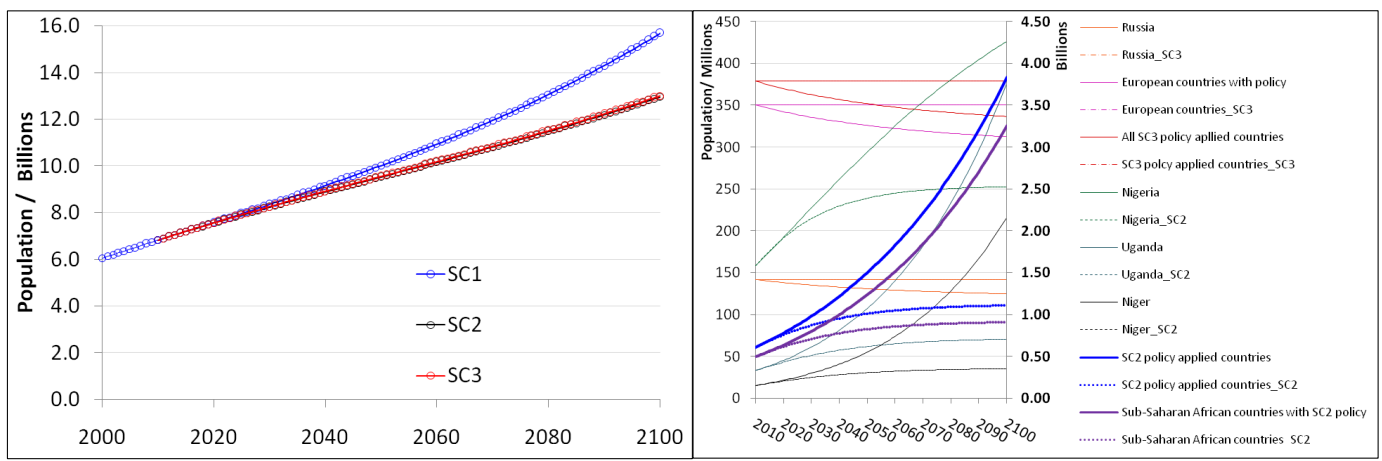

(a)

(b)

Fig. 1. (a) The population policy scenarios utilized in the study. SC1 does not assume any population policy to reduce climate change impacts. SC2 applies fertility-reduction policies to countries where the annual population growth rate in 2010 exceeds $2.5 \%$. SC 3 additionally assumes that by the time the countries reach the replacement fertility rates, there will be no policy to keep populations stabilized at zero growth. (b) The regional population growth for the countries where the SC2 (dotted line) and SC3 (center line) policies are applied. The solid lines show the populations under the no-policy scenario, SC1. For the thicker lines, please refer to the bold secondary vertical axis in billions.

considered follows the World Bank (2012) country populations until 2010.

The population policy scenarios are applied only for selected countries (Fig. 1b). SC2, which focuses on fertilityreduction programs, is applied only for countries with population growth rates greater than $2.50 \%$ in 2010 (the average population growth rate for heavily indebted poor countries in 2010 is $2.56 \%$ and for sub-Saharan Africa only is $2.49 \%$; World Bank, 2012). SC1 assumes an above-replacementlevel fertility for these countries even until 2100, and it is the $\mathrm{SC} 2$ (or SC3) population policies that reduce them to nearreplacement fertility (or replacement fertility in SC3). Trends in the population growth rate similar to that of China at various stages of transition (Fig. 2) were applied to these countries based on their income category (World Bank, 2012). The effectiveness of the fertility-reduction programs was assumed to decrease with decreasing income of the country. China is a country with more than $30 \mathrm{yr}$ of experience in fertility-reduction policies in the form of family planning programs in combination with other incentive and disincentive programs (Peng, 2011). Although, its "one-child policy" is open to limitless critique, the same policy has been more flexible in rural China (Peng, 2011). Therefore, it is a good example of policy-driven population growth trends. SC3 assumes that by the time the countries reach the replacement fertility level, they have policies to keep the populations stabilized at that level, apart from the assumptions in SC2.

However, the global impacts of scenarios SC2 and SC3 do not differ greatly according to Fig. 1. Even the no-policy scenario, $\mathrm{SC} 1$, assumes that populations will reach nearreplacement fertility levels for the countries with lower population growth rates (lower than $2.50 \%$ in 2010 ) by 2100 , simulating small, above-zero population growth.

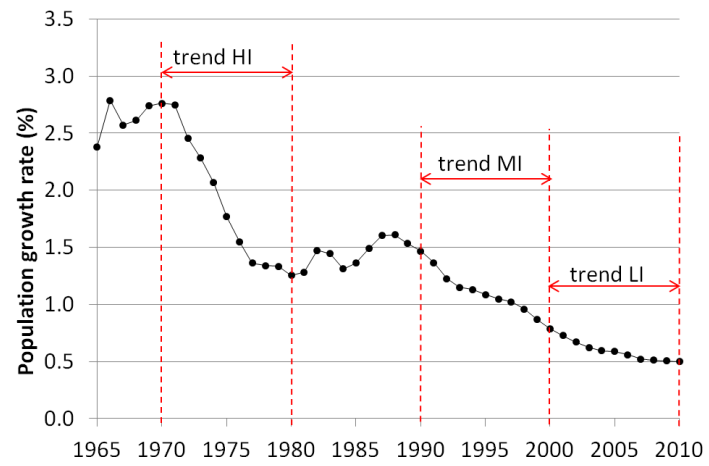

Fig. 2. The historical annual population growth rates in China (data from World Bank, 2012). The exponential trends for the marked periods were assumed to be driven by the fertility-reduction policy trends: HI, MI and LI in the annual growth rate under scenarios $\mathrm{SC} 2$ and SC3 for the selected countries in the respective income categories of high income, middle income and low income (World Bank, 2012).

\subsection{Future water availability scenarios used}

Water availability due to climate change was considered under emissions scenarios A1b, B1 and A2. However, only renewable water resources were considered for the analysis. The discharges per grid of horizontal resolution $0.5^{\circ}$ from the Total Runoff Integrating Pathways (TRIP-1) of the University of Tokyo were assumed to be the potentially available water for use in the respective grids. Validation of the TRIP data can be found in Oki et al. (2001) and Oki and Sud (1998).

Most land surface models (LSMs) tend to underestimate runoff in higher latitudes (Oki et al., 1999) because of the insufficiency of the forcing data and also partly because of the shortcomings of the physics considered in the LSMs (Oki 
et al., 2001). Oki et al. (2001) find their runoff estimates to be smaller approximately by a $20 \%$ compared to the previous studies. Routing runoff using TRIP improves seasonal cycle of river discharge, enhancing the correspondence with the observed discharge. However, the accuracy of simulated discharge depends on the accuracy of the forcing data.

The river discharge data were averaged over four climate models, CCSM3, MIROC3.2, CGCM2.3.2 and UKMO, for each climate scenario to reduce the effects of regional biases to the study. While many global climate models (GCMs) share the incapability of reproducing the Sahelian (West Africa) dry climate (Christensen et al., 2007) and of areas with complex relief (such as Tibet) (Christensen et al., 2007) with reasonable accuracy, many of them show regionally unique weaknesses in modeling the present/past climates in other regions (Wang et al., 2004; Cook and Vizy, 2006; Chiew et al., 2009). CCSM3 does not perform well in the Sahelian region (Africa) (Kamga et al., 2005), and both CCSM3 and UKMO do not generate the West African monsoon (Cook and Vizy, 2006). MIROC3.2 and CGCM2.3.2 do generate the West African monsoon and do model a drier climate, but still the accuracy is low (Cook and Vizy, 2006). In South Asia, MIROC3.2 is the only GCM (from above mentioned four GCMs) that shows good agreement in both annual cycles of precipitation and temperature, with a slight overestimation at peaks (Christensen et al., 2007). The only GCM that models the southeastern Australian rainfall is the UKMO model (Chiew et al., 2009), while the other three models show low spatial correlation and low variation of annual rainfall over the region, with low agreement in the rainfall trends (Chiew et al., 2009). Runoff generated by GCMs should also be affected by the above shortcomings. As our current study is at the global level, considering the above facts, utilization of a single GCM cannot be justified. Therefore, the discharge data produced using the outputs of the utilized 4 GCMs - CCSM3, MIROC3.2, (MRI) CGCM2.3.2 and UKMO model - were averaged to reduce the effects of the regional biases of these GCMs to our study. Averaging over GCMs is a very simple but common scientific method for global-level studies utilizing GCM data (Christensen et al., 2007).

The year 2000 was selected as the base year for the analysis. The per capita water resources $\left(\mathrm{m}^{3} \mathrm{yr}^{-1}\right)$ were calculated for all combinations of the population and climate scenarios.

Although the underlying population scenario utilized for the SRES A2 projects 15.1 billion people in 2100, similar to the population scenario employed in this study ( 15.7 billion in 2100), the other two projections are lower (IPCC, 2000; Arnell, 2004). Therefore, the climate scenarios were selected to represent the SRES high and low projection storylines (15.1 and 7.0 billion). However, as in the EMF-22 scenarios (Clarke et al., 2009, cited in Van Vuuren et al., 2010), no relationship was assumed between the climate scenarios and the population scenarios.

\subsection{Water stress indicator employed}

Falkenmark water stress indicator and the water resources vulnerability indicator (which takes the ratio of water use to availability) are the ones most commonly employed for climate change impact assessments on water (Vorosmarty et al., 2000; Arnell, 2004; Arnell et al., 2011; Murray et al., 2012). Both are calculated at the annual timescale, while the spatial scales could be the country scale (Arnell, 2004; Arnell et al., 2011), the watershed scale (Arnell et al., 2011) or the grid scale (Vorosmarty et al., 2000). While the water resource vulnerability indicator reveals the regions with high vulnerability, as a result of high water demands especially for agriculture, the Falkenmark water stress indicator masks these (Arnell et al., 2011). Nevertheless, Falkenmark water stress indicator's intuitive thresholds refer to the requirements indicated for households, and agricultural, industrial, and energy sectors as well as the needs of the environment as well (Rijsberman, 2006). It, therefore, provides a basis for distinguishing between climate- and human-induced water scarcity. Therefore, Falkenmark and Widstrand's (1992) water stress indicator was employed in the analysis. This indicator defines three levels of water stress: an annual per capita water availability of $0-500 \mathrm{~m}^{3} \mathrm{yr}^{-1}$ is extreme stress; 500 $1000 \mathrm{~m}^{3} \mathrm{yr}^{-1}$ is high stress; and $1000-1700 \mathrm{~m}^{3} \mathrm{yr}^{-1}$ is moderate stress (cited in Arnell, 2004). In addition, an upper transition zone of $1700-5000 \mathrm{~m}^{3} \mathrm{yr}^{-1}$ was defined to show the climate-population interactions in the middle to upper latitudes clearly. Our analysis was performed at the global level, while the effects of policies introduced were investigated at a finer scale.

\section{Results and discussion}

\subsection{Sensitivity of per capita water stress to the changes in the population growth assumptions}

The sources of uncertainty regarding the population and climate projections are numerous. Uncertainty in the base year population data is due to the unavailability of census records in some countries or regions in the year of concern. They have been estimated from the last available censuses (World Bank, 2012). Therefore, uncertainties of the base year populations are extremely heterogeneous across space. Uncertainties in the baseline climate and of the modeling parameters add to this. Above all, uncertainty is incomparably large in the future projections. Especially future population prospects of the African continent are highly uncertain, where many populations have not yet gone through transition, which are also characterized by high population momentums and high mortalities as well (Lee, 2011). Therefore, a sensitivity analysis was done in order to get an understanding of how the input data affect our desired output. 

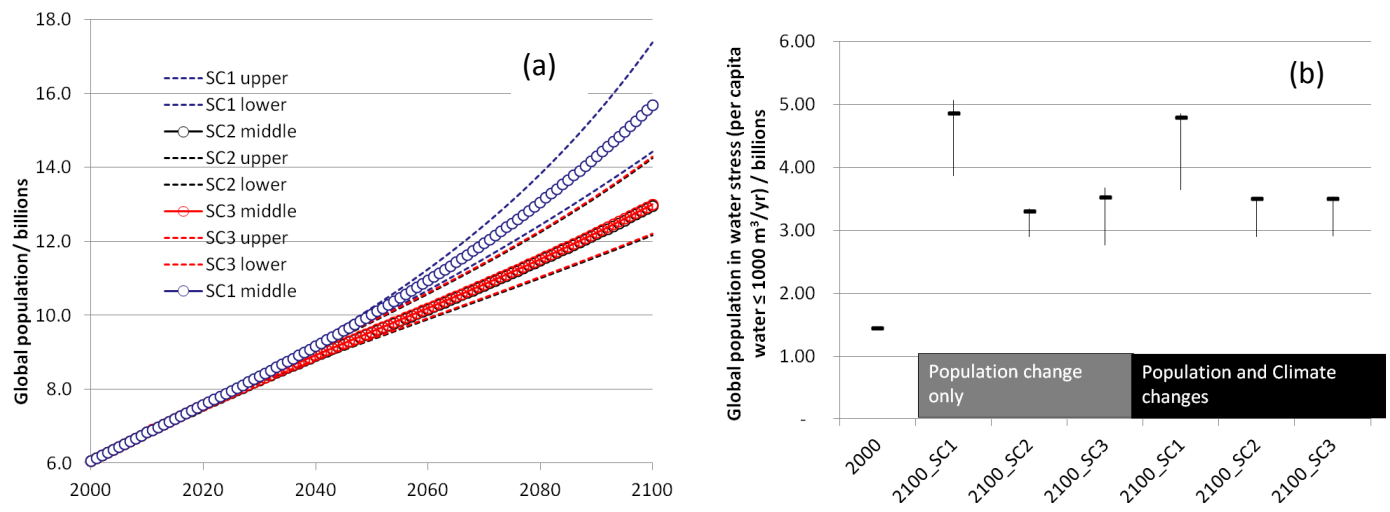

Fig. 3. (a) The population scenarios utilized for the sensitivity analysis. Small perturbations of \pm 0.01 were given for the assumed exponential decadal trends in population growth rates, to result in an upper and lower bound scenario each for the three population scenarios employed in the analysis. (b) The global population under water stress (per capita water available $\leq 1000 \mathrm{~m}^{3} \mathrm{yr}^{-1}$ ) in the year 2100 , SRES A1b, as a result of the sensitivity scenarios in (a). The base year 2000 stress is also shown.

Jiang and Hardee (2011) show how the UN medium population projections have varied since 1990 until 2006 (see Fig. 8 of Jiang and Hardee, 2011). The assumptions on which the future projections are built have been varying according to the physical evidence seen across the populations of concern. Building on this, trends of population growth rate were given very small perturbations of \pm 0.01 for high-income (HI) and middle-income (MI) countries, but low-income (LI) countries, most of which are African countries, were assigned \pm 0.02 . That is, uncertainty was assumed to be nonuniform over the different populations. Population projections were done for SC1, SC2 and SC3 scenarios, to produce upper and lower sensitivity regions (Fig. 3a) for the scenarios. To explore the effects on the per capita water stress, the population living in highly water stressed (per capita water $\leq 1000 \mathrm{~m}^{3} \mathrm{yr}^{-1}$ ) areas was calculated (Fig. 3b). Results are shown for SRES Alb.

Even though the chosen sensitivity ranges are quite distributed around the middle scenario, the resulting ranges of population living in water-stressed grids are very eccentric. There may be two reasons for this. One is that most population increase occurs in the already water-stressed regions, as agreed on by many other researchers (Vorosmarty et al., 2000; Arnell, 2004). The other could be the discrepancy between the underlying population scenario of SRES A1b, and our population scenarios used for the analysis (A1 scenario family uses a population scenario of about 7 billion at 2100). The eccentricity might be lower for B1 (underlying population of 10 billion at 2100) and for A2 (underlying population of 15 billion at 2100 , similar to ours of 15.7 billion). The difference of the impacts between the analyses with climate change and without does not render much difference. This might have been caused by the above two reasons as well. These will be further explored in the regional-scale analysis below and in the spatial analysis of the combined impacts of climate and population changes on water availability.
Whatever these reasons be, this eccentricity is caused by very high populations occurring at grids where water availability is low. According to our sensitivity analysis, a small reduction in population would release a large population from high water stress, while an increase in population might not increase the number of people under high water stress considerably. People who are already at extreme water stress might face even dire conditions of water availability. Therefore, this figure gives high imperative to use population policy to reduce the possibility of catastrophic water stress in the future.

\subsection{Major drivers of water stress and the effects of population policy seen at the regional level}

The effects of the population policies to increase (SC2 - population reduction policy) or to decrease (SC3 - population stabilization) per capita water availability and the combined effects of population and climate change were explored at the regional level in two regions (Fig. 4): one in Europe and the other on the African continent. The African region was chosen to indicate the effects of policy scenario SC2 (population reduction), while the European region was intended to show the effects of population stabilization in scenario SC3. Populations living in water-stressed (per capita water $\leq 1000 \mathrm{~m}^{3} \mathrm{yr}^{-1}$ ) grids were found under the population scenarios and the climate scenarios SRES A1b, B1 and A2 (Fig. 5). In order to investigate the comparative effects of the two drivers of water stress - water available and population - two more scenarios were introduced to model the effects only of population change and only of climate change.

If the populations living in water-stressed grids (the column charts in Fig. 5) under the three climate scenarios A1b, $\mathrm{B} 1$ and $\mathrm{A} 2$ are compared for each region, none of them stands out as different from the others, apart from small differences. Their scales and the projected ranges are almost comparable. Even though for the African region there are very high 
differences in projected populations under stress as a result of climate change only and of the combined population and climate changes ( $\mathrm{SC} 1)$, this is not even visible in the case of the European region. The effects of the population-only (under SC1) scenario give the maximum population living in water-stressed grids for all the climate scenarios. However, the combined climate and population scenario gives more or less the same impact. Therefore, the dominant driver of water stress in the African region is population, not climate change. The first two columns show the populations in waterstressed grids under 2000 populations, but the climate conditions are that of the baseline (2000) and that of 2100. When these two columns are compared across the three scenarios for the African region, the impact of A2 scenario is lower than of A1b or B1, even though they are of similar magnitudes. However, A2 is supposed to be the worst-case scenario of the three (Arnell, 2004; Shen et al., 2008). It might be because the population scenarios we have used for $\mathrm{Alb}$ and for B1 are different from their underlying family population scenarios (we used SC1 - no-policy scenario giving a 2100 global population of 15.7 billion for all the three climate scenarios). But for A2, they are almost the same. Therefore, the very strong population signal seen only in the African region is not a result of the discrepancy between the population scenarios used in our research and that used in the SRES scenario families, to produce the climate scenarios. The population under high water stress in 2100 for the European region is more than 20 times lower than that for the African region. This implies that using a very high population scenario quite different from the underlying population scenarios of the scenario families has made A1b and B1 scenarios highimpact scenarios in terms of water stress, only in the already water-stressed regions. This will be further elaborated in the next section, which addresses the spatial distribution of water stress over the world.

In the African region, where this study assumes that population reduction policies are in effect (SC2), the policies can reduce the populations living in highly water stressed (per capita water $\leq 1000 \mathrm{~m}^{3} \mathrm{yr}^{-1}$ ) regions up to one-third to onefourth. Therefore, for regions with high population growth and low water availability, it is population change that will impact the most, not climate change. In fact, climate impacts in both the African and the European regions are similar in scale (second column "Climate change only" of charts - Fig. 5).

Population stabilization policies increase populations by a few million in 2100 (3rd and 4th columns in the charts) for the European region, increasing populations under water stress as well. In this region, climate impact and the impact due to population increase are similar; implying other methods such as capacity building and institutional reforms might help to increase adaptive capacity of societies. Such programs as well might undermine the impacts of population stabilization on water availability. However, the scale of

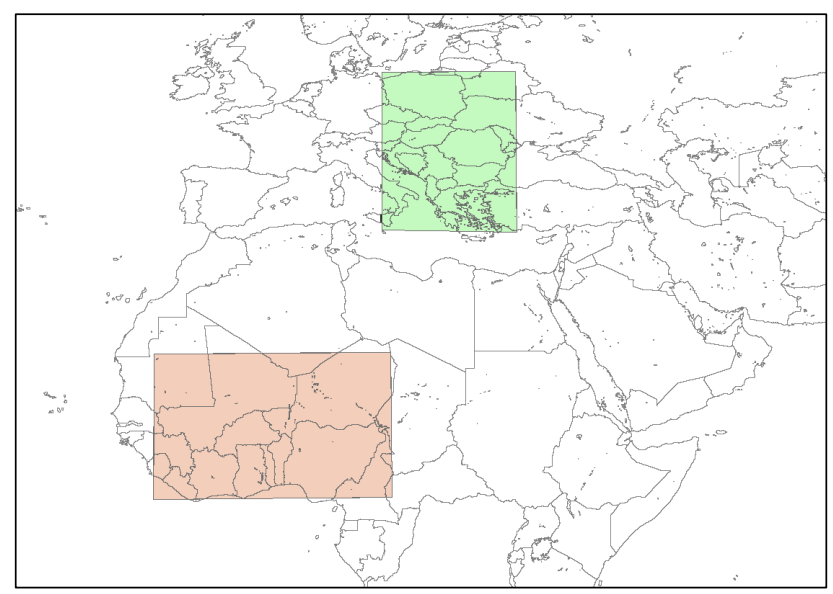

Fig. 4. The regions for which the smaller scale analysis was carried out. In the region on the African continent, our research utilized population reduction policies in scenario SC2. The scenario SC3 models population stabilization in some other parts of the world. The selected region in Europe addresses this aspect.

impacts on water availability in the European region is very small compared to the African region.

\subsection{The spatial distribution of the combined impacts of climate change and population change on water availability}

The spatial distribution of the impacts of population change under scenarios SC1, SC2 and SC3 for the water availability scenarios A1b, B1 and A2 was explored. Global per capita water availability $\left(\mathrm{m}^{3} \mathrm{yr}^{-1}\right)$ was calculated for grids with a horizontal resolution of $0.5^{\circ}$ for the base year 2000 and for the years 2025, 2050 and 2100, using the Falkenmark water stress indicator. The country-level population scenarios were disaggregated to the $0.5^{\circ}$ grid level using population counts per grid data for the year 2000 (corrected for the UN estimates) from the Centre for International Earth Science Information Network (CIESIN, 2010).

Figure 6 shows the per capita water availability from the combined effects of population and climate changes under the three climate scenarios in 2100 and how the population policy scenarios are beneficial or detrimental to regions addressing the impacts of climate and population changes. Figure 6a compares the effect of the no-policy population scenario (SC1) to the three climate scenarios A1b, B1 and A2 in the year 2100. The regions with high extreme water stress (per capita water available smaller than $1000 \mathrm{~m}^{3} \mathrm{yr}^{-1}$ ) are comparable to those of Murray et al. (2012). Nevertheless, the grid per capita water resources are not exactly the same due to the different data and projections utilized in that study. Therefore, the spatial extents cannot be compared exactly to that of Murray et al. (2012). 

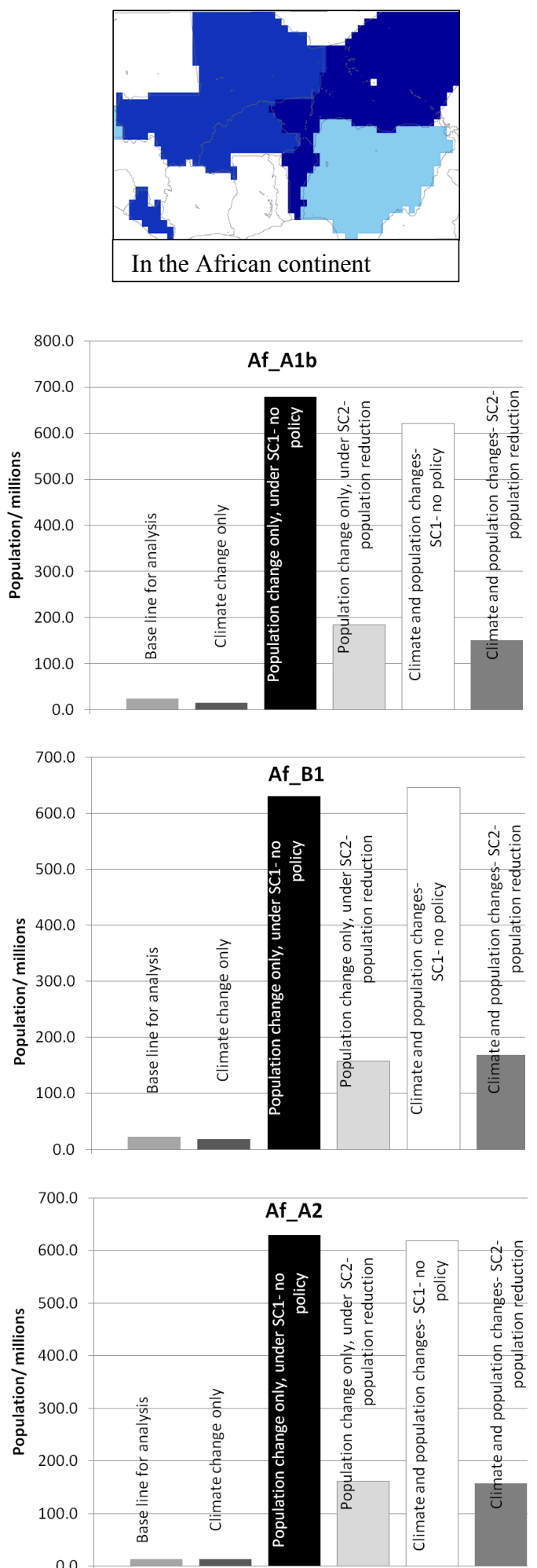
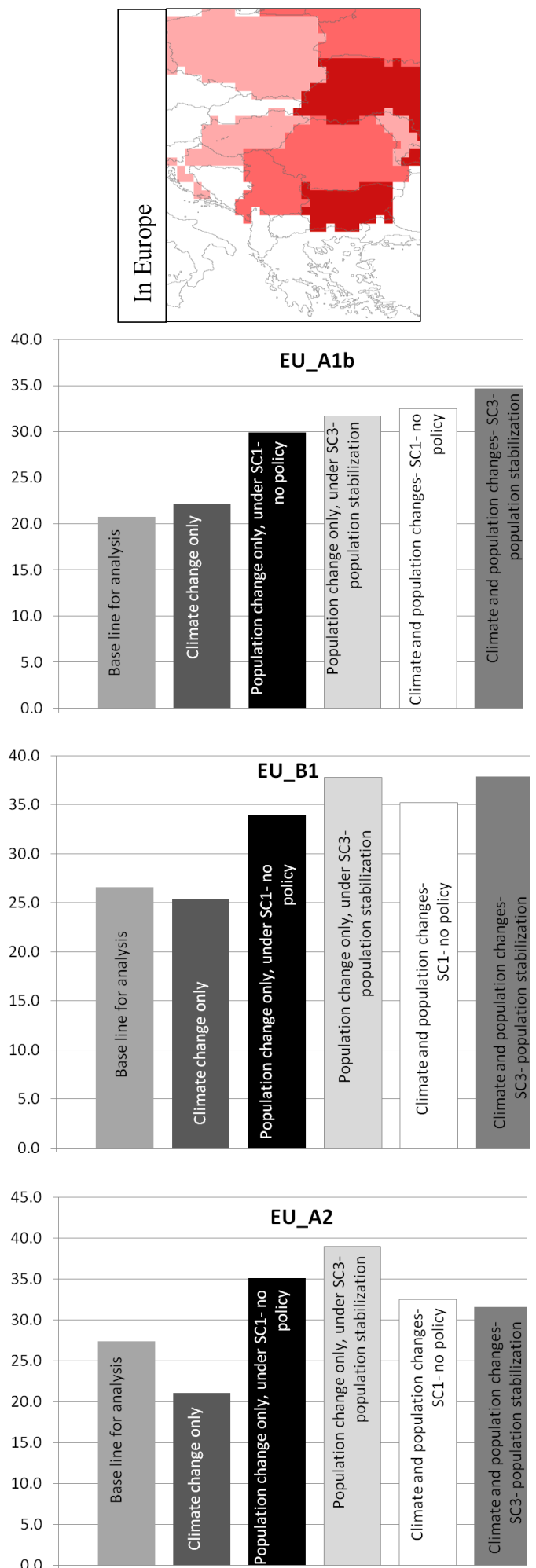

Fig. 5. The number of people living in water-stressed grids (per capita water $\leq 1000 \mathrm{~m}^{3} \mathrm{yr}^{-1}$ ) in the two regions analyzed. The effects of the population scenarios ( $\mathrm{SC} 1$ - no policy, SC2 - population reduction policy, SC3 - population stabilization in some regions while in some others population reduction is applied), and of the climate scenarios SRES A1b, B1 and A2 seen at the local level are investigated. $\mathrm{EU}$ - European region, Af - African region. The population used to calculate water stress for the first two columns is the baseline (2000) population, while for others 2100 populations were used. 


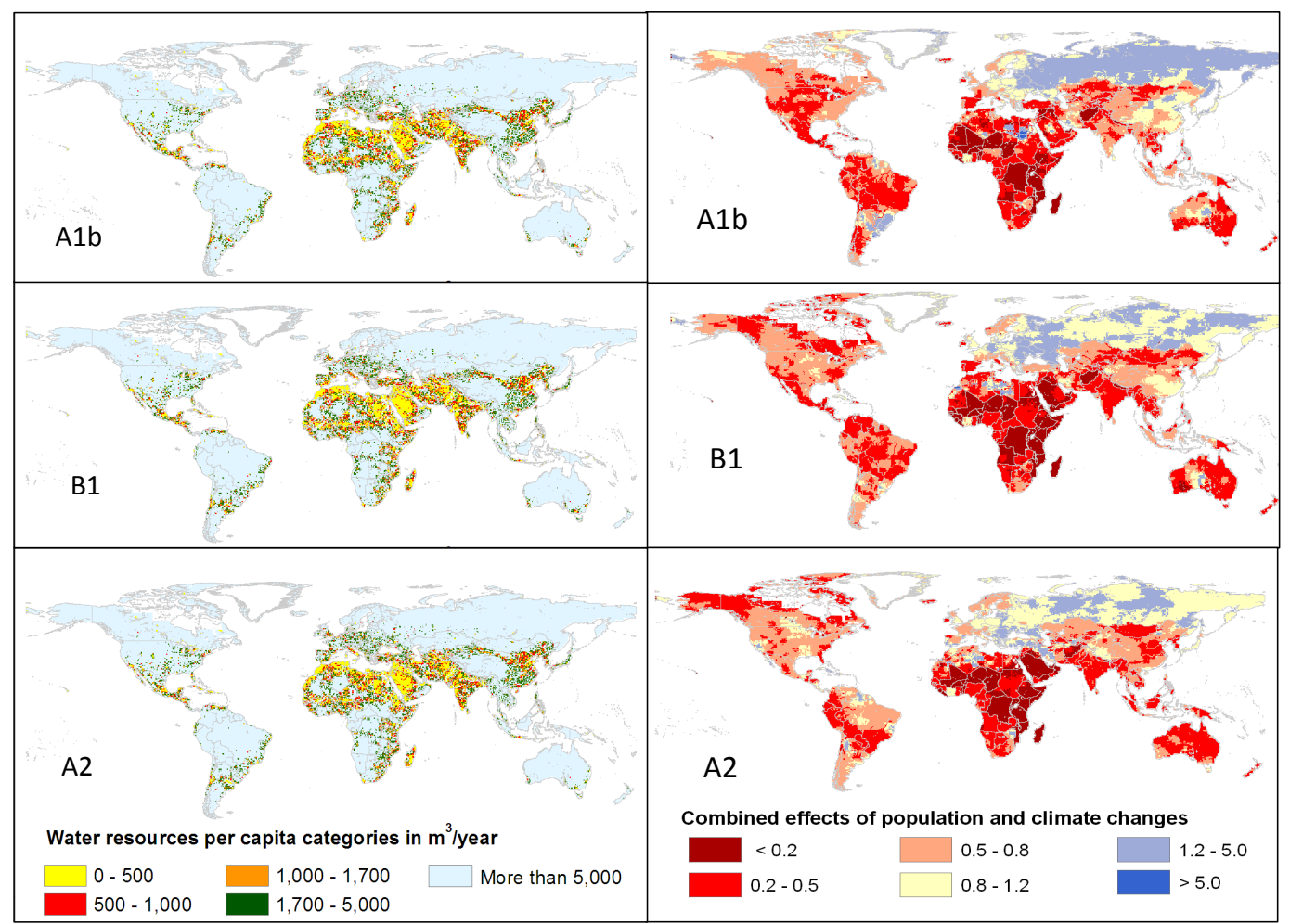

(a)

(b)

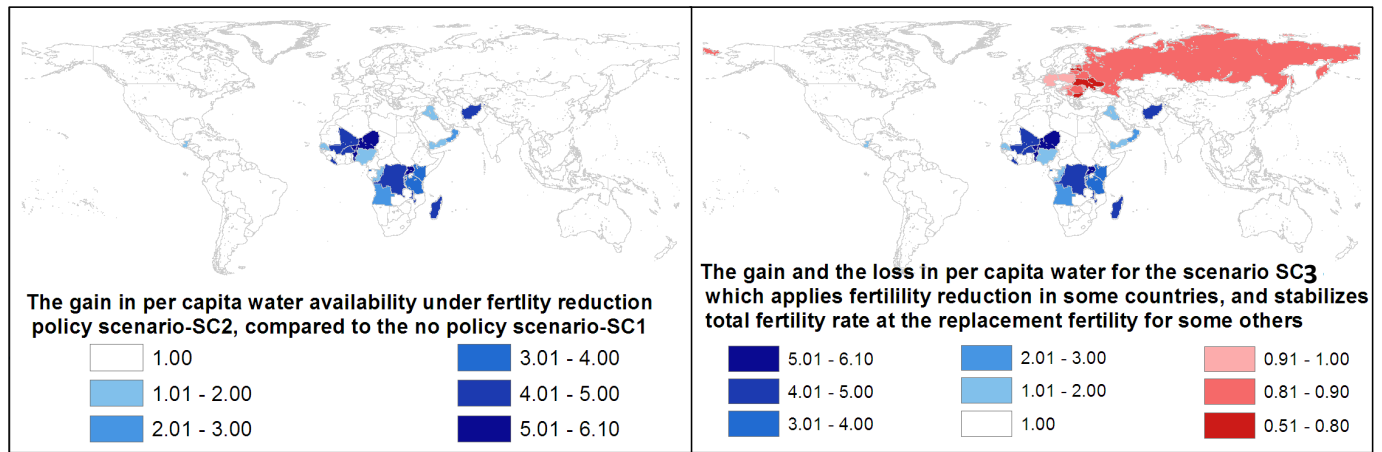

(c)

(d)

Fig. 6. The combined impact of population change and climate change for the year 2100 and the effectiveness of the population policy scenarios in reducing the impacts. The horizontal resolution is $0.5^{\circ}$. (a) Per capita water availability $\left(\mathrm{m}^{3} \mathrm{yr}^{-1}\right)$ in the world. The highest water stress categories are $0-500,500-1000$ and $1000-1700 \mathrm{~m}^{3} \mathrm{yr}^{-1}$, indicating countries where water stress is a major obstacle to human well-being and development or where water stress occurs regularly (Falkenmark and Widstrand, 1992). (b) The ratio of per capita water availability in $0.5^{\circ}$ grids in 2100 to that in the base year 2000.The yellow class $(0.8-1.2)$ assumes a change of $\pm 20 \%$ from the per capita water availability of 2000. (c) The gain in the per capita water availability given by the fertility-reduction policy scenario SC2 as the ratio between the per capita water for SC2 to that of SC1. (d) The gain (blue) or loss (red) in scenario SC3, which applies fertility reduction in certain countries and stabilizes the total fertility rate at the replacement fertility in certain others, compared to SC1, with the ratio of per capita water between $\mathrm{SC} 3$ and $\mathrm{SC} 1$.

Although A2 is expected to be the worst-case scenario (Arnell, 2004; Shen et al., 2008), in this case B1 in combination with the SC1 scenario (15.7 billion in 2100) also shows impacts similar to A2 for the already water-stressed lower latitudes. However, the B1 scenario, which has the same SRES population projection as in A1b (7.0 billion in 2100), shows a comparatively higher impact on the per capita water resources than A1b. This result implies that, opposed to the assumptions made in the SRES scenarios after 2050 (Arnell, 2004; Van Vuuren et al., 2010; Riahi et at., 2011), 
if combined with a more scattered pattern of population change across the world, a more convergent, environmentally friendly emissions scenario can result in a high-impact water stress scenario. This suggests a strong population signal compared to a very weak climate signal in the lower latitudes. The magnitude and the regions negatively affected $(<0.8$, Fig. $6 b)$ by the combined climate change and population change differ among the three climate change scenarios. However, all the three climate scenarios agree with the extremely negative impacts to water availability $(<0.5$ times water availability in 2000, Fig. 6b) on the African continent, the Middle East, Australia and in some parts of Asia. Therefore, the applied fertility-reduction scenario (SC2) addresses the projected extreme water availabilities.

Figure $6 \mathrm{c}$ and $\mathrm{d}$ show the gain or loss that could occur under the fertility-reduction policy scenario SC2 and the effects if it is combined with population stabilization at replacement fertility (scenario SC3), respectively. The scenario SC2 gives the highest gain (Fig. 6c), with 6.1 times the water resources per capita in Niger, compared with SC1, with the secondhighest gain of 5.3 times in Uganda. Niger and Uganda are the countries with the highest momentum for future population increase in sub-Saharan Africa. In 2100, these two countries represent $12.5 \%$ of the total population in the region. The fertility-reduction policy scenario $\mathrm{SC} 2$ reduces this figure to $4.5 \%$. The countries with fertility-reduction policies (SC2 - Fig. 6c) represent $24.5 \%$ of the global population in 2100 under the no-policy (SC1) scenario. Under $\mathrm{SC} 2$, this figure is reduced to $8.7 \%$. However, the benefits of $\mathrm{SC} 2$ far outweigh the losses due to population stabilization at replacement fertility (SC3). A decrease in the annual per capita water availability of half $(0.5)$ can be more detrimental than a twofold increase (Arnell, 2004), especially for regions with moderate to high water stress (annual per capita water $<1700 \mathrm{~m}^{3} \mathrm{yr}^{-1}$ ). However, the countries negatively affected by population stabilization at replacement fertility in $\mathrm{SC} 3$ are all high-latitude countries, including Russia and Eastern European countries with low water stress (annual per capita water $>1700 \mathrm{~m}^{3} \mathrm{yr}^{-1}$ ).

It is clear that any attempt taken to mitigate or adapt to climate change effects in the lower latitude regions with extreme water stress will probably have very little impact on future water stress if those do not focus on reducing the population pressure on water resources. In fact, reducing the population pressure alone might benefit these regions to a greater extent. If the population policies were combined together with the technological advancements in water resource management gained until present (Koutsoyiannis, 2011), the effectiveness in reducing extreme water stress could be much higher. Interestingly, these are the regions that are lower in economic strength and therefore are unable to contribute to the global greenhouse gas (GHG) emission reductions significantly. Nevertheless, population reduction policy will be a robust and independent approach to gain more control over their future development paths.

\subsection{Effectiveness of the population policy in reducing the impacts of climate change and population change in the policy-applied countries}

The combined population and climate changes increase water stress steadily in the countries where the population growth rates are high $(>2.5 \%)$ under the no-policy (SC1) scenario.

However, all three climate scenarios, A1b, B1 and A2, exhibit similar impacts on increased water-stressed areas in these countries (Fig. 7). In the extreme $\left(0-500 \mathrm{~m}^{3} \mathrm{yr}^{-1}\right)$ and high (500-1000 $\left.\mathrm{m}^{3} \mathrm{yr}^{-1}\right)$ water stress categories, the highest impact is given by the A2 scenario in 2100 . The other two scenarios follow. As seen in Fig. 6a, by 2100 (after 2050) the B1 scenario sometimes gives a higher impact (Fig. 7b and d), whereas A1b surpasses B1 at other times. The most important outcome is that the effect of population change supersedes the changes in climate scenarios.

Being in the regions (Fig. 6c) where $24.5 \%$ of the population is concentrated in 2100 , fertility-reduction programs could be considered a low-regret measure to address future water stress. However, a comparison of the reductions in the water-stressed area shows that $\mathrm{SC} 2$ and $\mathrm{SC} 3$ have parallel reduction paths, in contrast to the $0-500 \mathrm{~m}^{3} \mathrm{yr}^{-1}$ extreme water stress category, where $\mathrm{SC} 2$ is more effective at reducing the impact under the climate scenarios A2 and B1. This result occurs because most of the grids in the 0 $500 \mathrm{~m}^{3} \mathrm{yr}^{-1}$ stress category are in the lower latitudes, where only fertility-reduction policies (SC2) are applied. However, the SC3-applied areas under each stress category are higher than even the no-policy scenario areas simply because the $\mathrm{SC} 3$ region is larger than the SC2 region (Fig. 6d).

\subsection{The population policy and fertility-reduction programs of greater potential}

Although this study assumes the effects of population policies of a certain nature, identifying the types of population policies that will result in this form of benefit for a certain country is beyond the scope of the current study. However, a brief review of the existing policies that exhibit a greater potential for fertility decrease is provided here.

Among the various population policies employed to date, two emerge as the most effective in facilitating fertility decline: improving access to family planning services and educating the high-priority groups consisting of young women and mothers (O'Neil et al., 2001; Bongaarts and Sinding, 2011; Lutz and Samir, 2011, United Nations, 2011b). For the programs to be successful, improving access to contraceptive methods should accompany education programs, especially to eliminate the exaggerated fear of side effects, and family counseling services, to reduce opposition from spouses (Bongaarts and Sinding, 2011). In fact, this approach has proven to be highly effective even in the most traditional societies (Bongaarts and Sinding, 2011). Women with higher 


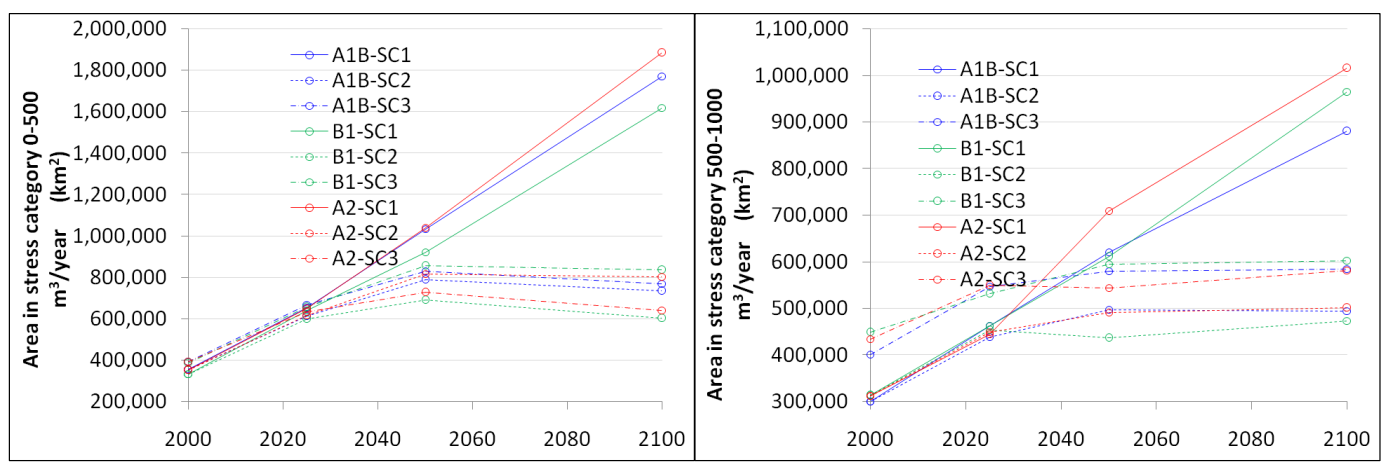

(a)

(b)

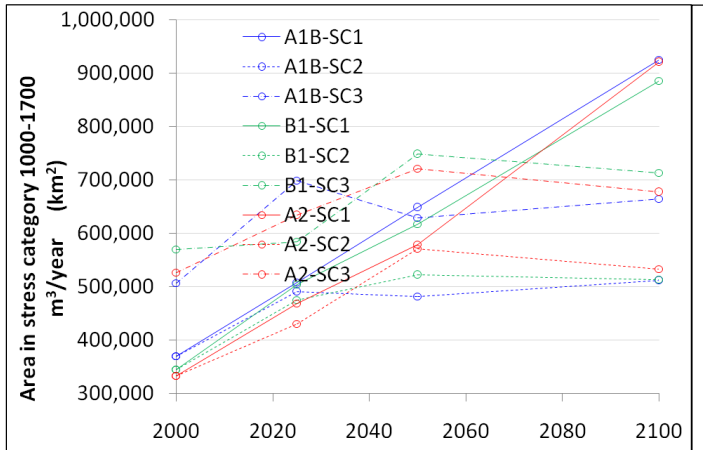

(c)

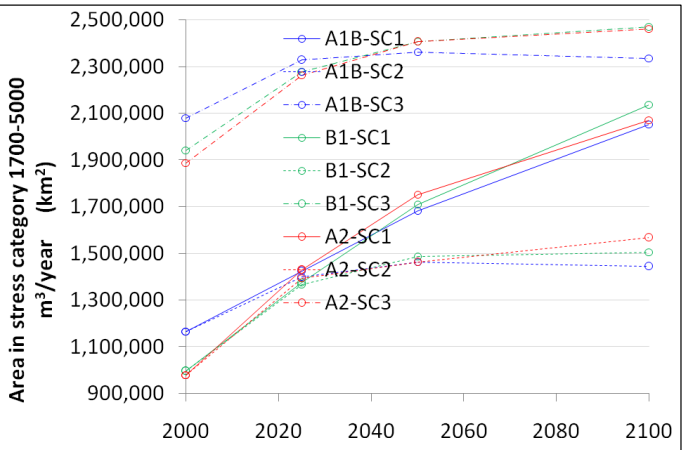

(d)

Fig. 7. The effectiveness of the population control policies (SC2 - fertility-reduction policy, SC3 - policy of population stabilization at replacement fertility) at reducing the area under water stress compared with the no-policy scenario, SC1. The figures consider only the countries for which the policies were applied (Fig. 3c for SC1 and SC2, Fig. 3d for SC3). The climate scenarios are indicated according to color: A1b - blue, B1 - green and A2 - red. The lines indicate the population scenarios under each climate scenario: SC1 - continuous lines, SC2 - dotted lines and SC3 - center lines.

levels of education have a lower desired fertility (O'Neil et al., 2001; United Nations, 2011b). Therefore, government spending on women's education is an indirect but highly effective strategy for achieving fertility rate decline. Providing incentives for women to join the labor force, as implemented by Japan (Samuel, 1966) and by China (Peng, 2011), also gives incentives to women to lower their desired fertility. However, governments are reluctant to interfere openly (O'Neil et al., 2001) with the fundamental reproductive rights of couples and individuals (United Nations, 2011b). Nevertheless, setting a higher minimum marriage age (United Nations, 2011b), which increases the mother's age at first birth, and China's "one-child policy" (Peng, 2011) could be considered instances in which governments intervened in the fertility decisions of individuals.

\section{Conclusions}

The effectiveness of population policy scenarios in reducing combined population change and climate change impacts was explored. The impact considered was increasing water stress, measured by the Falkenmark water stress index. Water resource availability under three climate scenarios, A1b,
B1 and A2, was considered along with a population scenario projected at 15.7 billion in 2100 . Two other population scenarios evaluated the strength of the fertility-reduction policy (SC2) and its combination with population stabilization with replacement fertility (SC3) to reduce future impacts on water resources. Unlike the population growth scenarios utilized in climate research, which use regionally uniform population growth rates after 2050, the scenarios in this study assume trends in the population growth rates regionally, even after 2050 .

For countries with high water stress (annual per capita water $<1700 \mathrm{~m}^{3} \mathrm{yr}^{-1}$ ), the climate change effects are far outpaced by the population change effects. The fertilityreduction policy scenario assumes policy only for a number of countries with high population growth rates. Most of these countries belong to sub-Saharan Africa. These countries represent $24.5 \%$ of the global population in 2100 , a value that is reduced to $8.7 \%$ under the scenario with fertility-reduction policy assumptions, SC2. SC2 reduces water stress in these countries significantly, although it is most effective at relieving the extremely water-stressed (annual per capita water $<500 \mathrm{~m}^{3} \mathrm{yr}^{-1}$ ) regions. However, the SC3 policy scenario slightly increases the pressure on water resources for Russia 
and for a few Eastern European countries, in addition to the benefits given by the SC2 assumptions. Still, Russia and the European regions remain under low or no water stress.

Nevertheless, the two scenarios do not differ greatly on a global scale.

The effects of population growth supersede the changes in the climate scenarios, especially at the already waterstressed lower latitudes. The sensitivity analysis revealed that a small reduction in populations over the region could relieve a large number of people from high water stress. Most of the population increase towards 2100 occurs at the already water-stressed lower latitudes. Therefore, population reduction policies are recommended for this region as a method of alleviating very high water stresses in the future. However, for the European region, the population under waterstressed regions is almost 20 times lower than that in the lower latitudes.

The climate scenario B1, in combination with a population scenario with a heterogeneous pattern of population growth opposed to the regional growth assumptions in the current climate scenarios, outpaces the impacts from the Alb scenario in the regions with high water stress.

At the current state of this research, uniform population growth rates were assumed across each country. Both population change and water availability do not vary below $0.5^{\circ}$ as well. Even though we looked at the water availability and a general human requirement of water through the Falkenmark index and its water stress classes, the actual water demand of a region could be far more deviated than what is assumed, largely due to different land use. The use of the water availability to demand ratio alongside will enable this research to give policy implications at finer scales. However, with these modifications, this study would be very informative at the local-level decision making. Consideration of future migration trends into the population projections would refine the decision making process at the local scale. The social factors such as conflicts hinder proper water management, thus affecting the water availability. However, incorporating them into the future projections of water availability is a very complex task. Nevertheless, the complexity that would be introduced to the study by these improvements would be enormous.

Population policies were proved highly effective at facilitating adaptation to the combined impacts of population change and climate change in the countries with the highest population momentum in the future, including Uganda, Niger and Nigeria. Population reduction policies will facilitate more control over their future development pathways, even if these countries were not able to contribute significantly to GHG emission cuts due to economic constraints. Even though the effects of the fertility-reduction policies were assumed to be similar to those of China during its population transitions, female education and increased access to contraceptive methods are accepted as more effective and attractive strategies for lowering fertility rates.
Supplementary material related to this article is available online at http://www.hydrol-earth-syst-sci.net/ 17/4429/2013/hess-17-4429-2013-supplement.pdf.

Acknowledgements. The authors thank the Environment Research and Technology Development Fund (S-8) of the Ministry of Environment, Japan, and the Ministry of Education, Culture, Sports, Science and Technology, Japan, for their assistance in this research.

Edited by: D. Koutsoyiannis

\section{References}

Arnell, N. W.: Climate change and global water resources: SRES emissions and socio-economic scenarios, Global Environ. Change, 14, 31-52, 2004.

Arnell, N. W., van Vuuren, D. P., and Isaac, M.: The implications of climate policy for the impacts of climate change on global water resources, Global Environ. Change, 21, 592-603, 2011.

Bongaarts, J. and Sinding, S.: Population policy in transition in the developing world, Science, 333, 574-575, 2011.

Chiew, F. H. S., Teng, J., Vaze, J., and Kirono, D. G. C.: Influence of global climate model selection on runoff impact assessment, J. Hydrol., 379, 172-180, 2009.

Christensen, J. H., Hewitson, B., Busuioc, A., Chen, A., Gao, X., Held, I., Jones, R., Kolli, R. K., Kwon, W.-T., Laprise, R., Magaña Rueda, V., Mearns, L., Menéndez, C. G., Räisänen, J., Rinke, A., Sarr, A., and Whetton, P.: Regional Climate Projections, in: Climate Change 2007: The Physical Science Basis. Contribution of Working Group I to the Fourth Assessment Report of the Intergovernmental Panel on Climate Change, edited by: Solomon, S., Qin, D., Manning, M., Chen, Z., Marquis, M., Averyt, K. B., Tignor, M., and Miller, H. L., Cambridge University Press, Cambridge, UK and New York, NY, USA, 2007.

CIESIN - Centre for International Earth Science Information Network: http://www.ciesin.columbia.edu/ last access: August 2010.

Clarke, L., Edmonds, J., Krey, V., Richels, R., Rose, S., and Tavoni, M.: International climate policy architectures: overview of the EMF 22 international scenarios, Energy Econ., 31, S64-S81, doi:10.1016/j.eneco.2009.10.013, 2009.

Cook, K. H. and Vizy, E. K.: Coupled model simulations of the West African monsoon system: twentieth- and twenty-first-century simulations, J. Climate, 19, 3681-3702, 2006.

Curtis, K. J. and Schneider, A.: Understanding the demographic implications of climate change: estimates of localized population predictions under future scenarios of sea-level rise, Popul. Environ., 33, 28-54, doi:10.1007/s11111-011-0136-2, 2011.

Das Gupta, M., Bongaarts, J., and Cleland, J.: Population, poverty and sustainable development - A review of the evidence, Policy Research Working Paper 5719, The World Bank, Washington, D.C., USA, 1-28, 2011.

Falkenmark, M. and Widstrand, C.: Population and Water Resources: A delicate balance, Population Bulletin, Population Reference Bureau, Washington, 1992.

IPCC: Summary for policy makers, in: Special Report on Emissions Scenarios, edited by: Nakicenovic, N. and Swart, R., Cambridge University Press, UK, 1-20, 2000. 
IPCC: Summary for Policymakers, in: Managing the risks of extreme events and disasters to advance climate change adaptation, A special report of working groups I and II of the Intergovernmental Panel on Climate Change, edited by: Field, C. B., Barros, V., Stocker, T. F., Quin, D., Dokken, D. J., Ebi, K. L., Mastrandrea, M. D., Mach, K. J., Plattner, G.-K., Allen, S. K., Tignor, M., and Midgley, P. M., Cambridge University Press, Cambridge, UK, and New York, NY, USA, 1-19, 2012.

Jiang, L. and Hardee, K.: How do recent population trends matter to climate change, Popul. Res. Policy. Rev., 30, 287-312, doi:10.1007/s11113-010-9189-7, 2011.

Kamga, A. F., Jenkins, G. S., Gaye, A. T., Garbe, A., Sarr, A., and Adedoyin, A.: Evaluating the Natural Center for Atmospheric Research climate model over West Africa: Present-day and the 21 st century A1 scenario, J. Geophys. Res., 110, D03106, doi:10.1029/2004JD004689, 2005.

Koutsoyiannis, D.: Scale of water resources development and sustainability: Small is beautiful, large is great, Hydrolog. Sci. J., 56, 553-575, 2011.

Koutsoyiannis, D., Makropoulos, C., Langousis, A., Baki, S., Efstratiadis, A., Christofides, A., Karavokiros, G., and Mamassis, N.: HESS Opinions: "Climate, hydrology, energy, water: recognizing uncertainty and seeking sustainability", Hydrol. Earth Syst. Sci., 13, 247-257, doi:10.5194/hess-13-247-2009, 2009.

Lee, R.: The outlook for population growth, Science, 333, 569-573, 2011.

Lutz, W. and Samir, K. C.: Global human capital: Integrating education and population, Science, 333, 587-592, 2011.

Moss, R. H., Edmonds, J. A., Hibbard, K. A., Manning, M. R., Rose, S. K., Van Vuuren, D. P., Carter, T. R., Emori, S., Kainuma, M., Kram, T., Meehl, G. A., Mitchell, J. F. B., Nakicenovic, N., Riahi, K., Smith, S. J., Stouffer, R. J., Thomson, A. M., Weyant, J. P., and Wilbanks, T. J.: The next generation of scenarios for climate change research and assessment, Nature, 463, 747-756, doi:10.1038/nature08823, 2010.

Murray, S. J., Foster, P. N., and Prentice, I. C.: Future Global Water Resources with respect to Climate Change and Water Withdrawals as estimated by a Dynamic Global Vegetation Model, J. Hydrol., 448-449, 14-29, 2012.

NRC - National Research Council: Commission on Behavioral and Social Sciences and Education, Beyond six billion: Forecasting the world's population, edited by: Bongaarts, J. and Bulatao, R. A., National Academic Press, Washington, D.C., 2000.

Oki, T. and Sud, Y. C.: Design of Total Integrating Pathways (TRIP) - a global river channel network, Earth Interact., 2, 1-36, 1998.

Oki, T., Nishimura, T., and Dirmeyer, P.: Assessment of land surface models by runoff in major river basins of the globe using Total Runoff Integrating Pathways (TRIP), J. Meteorol. Soc. Jpn., 77, 235-255, 1999.
Oki, T., Agatha, Y., Kanae, S., Saruhashi, T., Yang, D., and Musiake, K.: Global assessment of current water resources using Total Runoff Integrating Pathways, Hydrolog. Sci. J., 46, 983-995, 2001.

O’Neill, B. C., MacKellar, F. L., and Lutz, W.: Population and climate change, Cambridge University Press, UK, 2001.

Peng, X.: China's demographic history and future challenges, Science, 333, 581-587, 2011.

Riahi, K., Rao, S., Krey, V., Cho, C., Chirkov, V., Fischer, G., Kindermann, G., Nakicenovic, N., and Rafaj, P.: RCP 8.5 - A scenario of comparatively high greenhouse gas emissions, Climatic Change, 109, 33-57, 2011.

Rijsberman, F. R.: Water scarcity: fact or fiction?, Agr. Water Manage., 80, 5-22, 2006.

Samuel, T. J.: Population control in Japan: lessons for India, Eugen. Rev., 58, 15-22, 1966.

Shen, Y., Oki, T., Utsumi, N., Kanae, S., and Hanasaki, N.: Projection of future world water resources under SRES scenarios: water withdrawal, Hydrolog. Sci. J., 53, 11-33, 2008.

United Nations, Department of Economic and Social Affairs, Population Division: World Population Prospects: The 2010 Revision, Volume II: Demographic Profiles, ST/ESA/SER.A/317, New York, USA, 2011a.

United Nations, Department of Economic and Social Affairs, Population Division: Seven billion and growing: the role of population policy in achieving sustainability, Technical Paper No. 2011/3b, New York, USA, 2011 b.

Van Vuuren, D. and O'Neill, B. C.: The consistency of IPCC's SRES scenarios to recent literature and recent projections, Climatic Change, 75, 9-46, doi:10.1007/s10584-005-9031-0, 2006.

Van Vuuren, D., Riahi, K., Moss, R., Edmonds, J., Thomson, A., Nakicenovic, N., Kram, T., Berkhout, F., Swart, R., Janetos, A., Rose, S., and Arnelll, N.: Developing new scenarios as a common thread for future climate research, Joint IPCC Workshop of Working Group III and II on Socioeconomic Scenarios for Climate Change Impact and Response Assessments (WoSES), Berlin, Germany, 1-3 November 2010.

Vorosmarty, C. J., Green, P., Salisbury, J., and Lammers, R. B.: Global water resources: vulnerability from climate change and population growth, Science, 289, 284-288, 2000.

Wang, B., Kang, I., and Lee, J.: Ensemble simulations of AsianAustralian monsoon variability by 11 AGCMs, J. Climate, 17, 803-818, 2004.

World Bank: http://data.worldbank.org/, last access: February 2012. 